\title{
The Most Common Discomfort
}

\author{
Edith María Beltrán Molina*, Ana Beatriz Peña Mantilla and Frank Abel Ramos Escudero
}

Assistant Professor at the University of Sancti Spíritus, "José Martí Pérez", Cuba

Received: September 20, 2017; Published: October 04,2017

*Corresponding author: Edith María Beltrán Molina, Assistant Professor at the University of Sancti Spíritus, "José Martí Pérez", Cuba; Email: ebeltran@uniss.edu.cu

\section{Mini Review}

The present work refers to one of the discomforts that most affect the human organism: stress; it provides a definition of the term, the main hormones that are secreted and their effects, as well as some of the damage that can cause the human body that affect their internal balance and therefore their well-being.

\section{Where does the word stress come from?}

The term stress (from the Latin stringere 'squeeze') and its derivative in English stress (fatigue of material) arises from the investigations carried out by Hans Selye in the 1930s, who from the studies carried out to different patients determined that regardless of the disease they suffered, their symptoms coincided with fatigue, weight loss, appetite, frequent fatigue, physical and psychic weakness. The word stress comes from physics, science that is in charge of the study of energy, matter, time and space, in this case refers to the pressure exerted by one body on another, and the one that receives the most pressure can shatter. Selye's studies later led to the conclusion that stress is the nonspecific response to any demand to which the organism is subjected, to which he refers in his research entitled "Stress" published in 1950.

\section{What is stress?}

From the search in different bibliographic sources of what stress means we can say that it consists of a response given by the organism, can be positive or negative to a situation caused by factors coming from both the external or internal environment and can affect homeostasis. Positive stress is one that favors the body, that is, it allows solving a certain situation and adapting to the new conditions. Negative stress breaks the internal balance of the body (homeostasis) Causing Anxiety, Fatigue, Anger, Exhaustion and Irritability.

\section{What are the major hormones secreted in the face of stress?}

The consequences of stress impact on mood and health. In this situation several hormones are involved but the main ones are: adrenaline and cortisol. The first is responsible for giving us that fast momentum that we need. In a matter of moments, our energy goes up enormously to help us escape the danger, as a result breathing becomes faster and increases the heart rate so that the muscles respond more quickly, prevents blood clots, blood circulates more quickly, experience physical sensations such as tightness in the chest, palpitations, cold sweating, tingling in the stomach.

Cortisol allows that response of the body to a threatening stimulus lasts the time necessary to resolve a given situation and return to balance, that is, leaves the body "on alert", ready to react as quickly as possible, this indicates that Stress also has its useful side. The frequent exposure to stress increases the secretion day after day of these hormones to the blood which generates physical and psychic damages in the human organism that significantly affect the quality of life.

\section{What are the damages that can cause frequent stress?}

i. Tension headache: In addition to being produced by muscular contractures can be cause of stress; there is a pain in the whole head on a regular basis, the sensation is that something tightens the perimeter of the head. It improves a lot with physical activity and relaxation.

ii. Tic Nervous: Stress is a trigger of tics, can appear anywhere on the body, on the face, hands, arms, eyes, lips, neck, etc., depends on the body of the person and anxiety level. The less the case, the faster it disappears.

iii. Atopic dermatitis: It can be triggered in stressed people; is characterized by rash, redness, itching and burning. The skin rebels against the excess of stress and causes in it such disorders.

iv. Obesity and overweight: It is the fifth cause of human death in the world. Being in constant stress, the person does not limit the intake of foods high in calories, since it seeks to satisfy their emotional needs, this brings with it a hypertrophy of the adipose tissue of the body and triggers cardiovascular diseases, diabetes mellitus, osteoarthritis, among others.

v. Hair loss: This is one of the frequent consequences of stress, as it is presented by weakening hair follicles or anxiety to pull hair to deal with negative feelings. 
vi. Depression: Stressful situations increase the risk of suffering from this disease. The problems to face the tension generate physical wear, bad mood and feelings of sadness.

\section{Anger and aggression}

a. 8-Reduction of sexual desire: High production of cortisol reduces the generation of hormones that feed the libido, an affective disorder of depressive cutoff.

b. Irregular menstruation: Chronic stress damages the hormonal balance of the body, which leads to delays or absences of the menstrual flow. Even some studies say that women with stressful jobs are $50 \%$ more likely to have short periods.

c. Acne: Chronic and inflammatory skin disease that can be caused or aggravated by stress, since the secretion of high levels of cortisol that are generated by stress increase the production of sebum which obstructs the pores favoring the appearance of grains.

d. Ulcers: Stress alters the digestive system in people and increases the production of stomach acids, which favors the development of ulcers, indigestion and malaise.

e. Insomnia: This is a frequent consequence of stress and is generated by the alteration of the nervous system, which hinders concentration, generates irritability and lack of motivation.

f. Cardiac diseases: When we are stressed the blood pressure increases, cholesterol levels and triglycerides in the blood are altered, causing cardiovascular disorders.

g. Memory problems: Stress acts on the brain causing serious damage. When cortisol levels remain high for a long time an area in the brain able to control short term memory is markedly reduced.

h. Increase of vices: Stress stimulates unhealthy behaviors like smoking, substance abuse such as alcohol or drugs, further increasing the oxidative processes in the person. These defects attack the organism, at the cardiovascular level, at the immunological level, at the level of the central and peripheral nervous system, at the gynecological level, at the psychological level, at the level of the respiratory system, at the blood level, at the gastrointestinal level, at the dermal level, at social level, among others [1-9].

\section{How to fight stress?}

Every person should have identified those factors that generate tension and act accordingly using the methods or techniques that are most beneficial to combat the effects of stressors, for example: breathing exercises of relaxation, recreation, maintaining a healthy diet, a pleasant climate, avoid worries, organize time, take things slowly, perform physical exercises, maintain a positive attitude to problems, avoid the pressures of daily life. There are other techniques such as laughter therapy which allows the release of endorphins that are neurotrasmores that modulate pain, aromatherapy which is an alternative therapy based on the perception of the essential oil odors that allow relaxation and act in the face of depression and auriculotherapy that consists of locating points in the auricular pavilion for the treatment of diseases.

All of the above helps to calm stress in overwhelming situations as well as to control the body physically and emotionally.

\section{References}

1. Cabral João Carlos Centurion, Veleda Gessyka Wanglon, Mazzoleni Martina, Colares Elton Pinto, Neiva Silva, et al. (2016) Stress and Cognitive Reserve as independent factors of neuropsychological performance in healthy elderly. Ciência \& Saúde Coletiva 21(11): 3499-3508.

2. El estrés y su salud: Medline Plus enciclopedia médica. Extraído de Página Principal Enciclopedia médica, U.S. National Library of Medicine, USA.

3. Hüther, Gerald (2012) Biología del miedo. El estrés y los sentimientos. Plataforma Editorial, Barcelona, Spain.

4. La tensión emocional, Extraído de, Spain.

5. Pérdida de (2017) memoria por estrés: Síntomas, causas y tratamieonto. Extraído de, Spain.

6. ¿Puede el estrés causar enfermedades cardiovasculares? (2008) Extraído de

7. Titus F, Acarín N, Dexeus S (2000) Cefalea. Ediciones Harcourt SA, Spain.

8. Webconsultas (2017) Controlar el estrés. Revista de salud y bienestar. Consultado el 15 de septiembre de, Spain.

9. Wikipedia 2017.

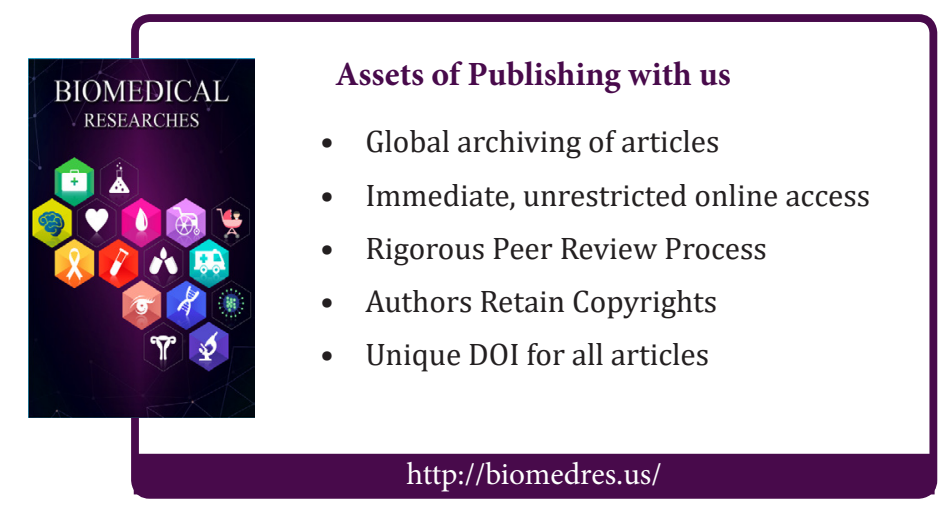

